\title{
Editorial do v. 27, n. 1 (2015): Lev Vigotski e a teoria histórico- cultural no Brasil: alguns relatos de pesquisas
}

\author{
Zoia Prestes, ${ }^{I, \star}$ Jader Janer Moreira Lopes ${ }^{I I}$ \\ ${ }^{I}$ Universidade Federal Fluminense, Niterói, RJ, Brasil

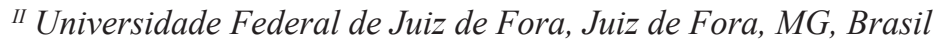

O veresk sobrevive no solo mais infértil e prepara este solo para as plantas mais exigentes. (VIGODSKAIA; LIFANOVA, 1996).

\begin{abstract}
A teoria histórico-cultural soviética, desenvolvida na década de 1920, por Lev Semionovitch Vigotski, Aleksandr Romanovitch Luria e Aleksei Nikolaievitch Leontiev surgiu na confluência de problemas que a jovem União Soviética enfrentava à época. Naquele momento, estava em pauta não apenas a organização de uma nova sociedade justa e igualitária, mas, principalmente, a educação do novo homem que seria participante ativo da nova sociedade em construção. Apesar de ter sido desenvolvida há quase um século e ter sido pensada num contexto histórico específico, a abordagem, que assumiu a discussão a respeito da necessidade de uma nova psicologia e de uma nova escola, ainda hoje se apresenta atual. Prova disso é o número expressivo de pesquisas que ainda hoje são realizadas com base em seus postulados no Brasil e em outros países.
\end{abstract}

Ao lançarmos o olhar sobre a história da divulgação no Ocidente das obras dos mais destacados representantes da teoria histórico-cultural, é possível observar que alguns nomes são bem conhecidos, mas outros permanecem como "ilustres desconhecidos" e, na maioria das vezes, são apenas citados por terem sido colaboradores ou alunos de Vigotski, Luria ou Leontiev. No entanto, mesmo as obras destes sofreram com as censuras e cortes impostos tanto em seu país de origem como no Ocidente. O linguista mundialmente conhecido Roman Ossipovitch Iakobson disse, em depoimento gravado durante o Congresso Internacional realizado em Tbilissi em 1979, ter sido a pessoa que levou os estudos de Vigotski para o Ocidente, numa época em que poucos se interessavam pelos estudos que estavam sendo realizados na URSS. Por sua vez, Stefan Tulmin afirma que a publicação das obras de Vigotski nos Estados Unidos na década de 1990 evidenciava que seus estudos, realizados nos anos de 1920 e 1930, eram muito atuais e guardavam relação com os trabalhos de pesquisadores norte-americanos do final do século XX (IAKOBSON apud LEVITIN, 1990). A partir de então, teve início o trabalho de traduções dos volumes das Obras Selecionadas de Vigotski publicados no início dos anos 1980 na URSS.

E foi por meio das traduções norte-americanas que o mundo ocidental passou a conhecer a teoria histórico-cultural; com base nelas foram feitas traduções e publicações em diversos países, inclusive no Brasil e na Alemanha. Atualmente, existem estudos que revelam a trajetória das traduções dos trabalhos de L. S. Vigotski no Brasil e que apontam para a necessidade de rever as traduções e a compreensão de conceitos basilares do seu pensamento (ver PRESTES, 2012). Ao mesmo tempo, na Rússia, estão sendo publicados livros que têm por base os textos originais de Vigotski e dos principais representantes de sua teoria, pois a grande maioria havia sofrido censura e cortes em diferentes épocas e por diversos motivos, sobretudo ideológicos.

Em função do exposto, no mês de agosto de 2013, organizou-se um evento na Universidade Federal Fluminense, com o título de VERESK, que reuniu pesquisadores que desenvolvem estudos sobre a teoria histórico-cultural.

O nome VERESK foi escolhido em homenagem à revista de arte editada por Vigotski em 1922. Seu principal objetivo era agrupar os atores, artistas plásticos, músicos, poetas, escritores e chamar a atenção para as questões da arte. A revista intitulava-se VERESK e trazia como primeiras palavras a epígrafe que abre essa introdução, evidenciando a força e a potência de uma planta, que brota e floresce logo depois do inverno no interior do continente euroasiático. Pode-se fazer um paralelo com a teoria histórico-cultural que sobreviveu às intempéries em diferentes momentos de sua história e até hoje continua pautando pesquisas científicas no campo das Ciências Humanas no mundo todo.

Para o I ${ }^{\circ}$ Veresk foram convidados professores do Brasil, da Rússia e da Alemanha com experiência em pesquisas acadêmicas que têm como base os trabalhos de Vigotski, Luria, Leontiev, Elkonin, Bojovitch, Zaporojets, Slavina, Levina, entre outros.

O evento também foi uma oportunidade para aproximação da Universidade Federal Fluminense com universidades brasileiras e estrangeiras (Universidade Federal do Rio de Janeiro, Universidade de Brasília, Universidade Federal de Mato Grosso, Centro Universitário de Brasília, Universidade de Siegen, da Universidade Russa de Humanidades e Universidade Estatal de Gomel), estreitar laços entre diversos grupos de estudos e pesquisas e ampliar o diálogo teórico e prático que possam contribuir na busca de achados pertinentes aos temas abordados, produzir material e referências para a área da educação e outros campos de conhecimentos.

^Endereço para correspondência: Universidade Federal Fluminense, Faculdade de Educação. Campus Gragoatá - Bloco D. Gragoatá. CEP: 24210-201 - Niterói, RJ Brasil.E-mail: zoiaprestes@yahoo.com.br, jjanergeo@gmail.com 
Para o desenvolvimento das atividades foram convidados Guenadi Kravtsov, Elena Kravtsova, Oleg Kravtsov, professores e pesquisadores da Universidade Russa de Humanidades/Rússia; Serguei Jerebtsov, professor da Universidade Estatal de Gomel/Beolorússia; Bernard Fichtner, professor da Universidade de Siegen/Alemanha, Elizabeth Tunes, professora do Centro Universitário de Brasília e Universidade de Brasília/Brasil.

Por se tratar da primeira versão, a comissão organizadora teve por opção não abrir para o público em geral a apresentação de trabalhos, mas procedeu-se o convite a diversos grupos de pesquisas para relatarem e debaterem suas atividades com os participantes.

Este número especial da Fractal: Revista de Psicologia agrupa os textos encaminhados para o evento e que serviram de base para ampliar as reflexões e os debates com todos que participaram do encontro. A publicação deste material faz um recorte de algumas temáticas que estão sendo trabalhadas no interior desses grupos, e a sua chegada aos diversos leitores do Brasil e claro, de outros países, permite enveredar por suas pesquisas, evidenciando o quanto os postulados e ideias desses teóricos se firmaram no espaço e no tempo.

Nós, organizadores desse evento e deste número especial, agradecemos publicamente à revista Fractal e ao corpo editorial a publicação deste exemplar, que em muito pretende contribuir com aquilo que Guita Vigodskaia tanto defendeu e acreditou: a segunda vida de um autor que começa após sua morte, como expresso em suas próprias palavras:

Após a morte de uma pessoa, começa sua segunda vida. Ela vive nos corações de quem a amava e nos trabalhos que realizou em vida. A vida de um cientista continua nos trabalhos que criou e nos seus alunos.

Guita Vigodskaia

\section{Referências}

LEVITIN, K. I. Litchnostiu nie rojdaiutsia. Moskva: Nauka, 1990.

PRESTES, Z. R. Quando não quase a mesma coisa: traduções de Lev Semionovitch Vigotski no Brasil. Campinas: Autores Associados, 2012.

VIGODSKAIA, G. L.; LIFANOVA, T. M. Lev Semionovitch Vigotski: jizn, deiatelnost, chtrirri k portretu. Moscou: Smisl i Smisl, 1996. 